\title{
Complete repair of total anomalous pulmonary venous connection in adult patient
}

\author{
Correção total da conexão anômala total das veias pulmonares em paciente adulto
}

\author{
Fernando A. ATIK ${ }^{1}$, Mauricio JARAMILLO ${ }^{2}$, Jorge Y. AFIUNE ${ }^{3}$, Luiz Fernando CANEO ${ }^{4}$
}

RBCCV 44205-1056

\begin{abstract}
A 22 year-old male patient was admitted with supracardiac, nonobstructive, total anomalous pulmonary venous connection and large atrial septal defect. Cardiac catheterization revealed severe pulmonary hypertension due to pulmonary overflow $(\mathrm{Qp} / \mathrm{Qs} 6$, pulmonary vascular resistance $=1.6 \mathrm{Woods} / \mathrm{m}^{2}$ ). Complete repair was performed through median sternotomy and cardiopulmonary bypass. The patient was discharged from hospital on the sixth postoperative day with no complications, using converting enzyme inhibitor and aspirin. At six-month follow-up he is currently asymptomatic, with preserved biventricular function and no echocardiographic signs of pulmonary hypertension.
\end{abstract}

Descriptors: Heart defects, congenital. Hypertension, pulmonary. Pulmonary veins/abnormalities.

\section{INTRODUCTION}

Pathophysiology of all anatomic forms of total anomalous pulmonary venous connection (TAPVC) relates to pulmonary venous return integrity and presence of intracardiac septal defects. The majority of patients present in the neonatal period with decompensated heart failure due to pulmonary overflow or pulmonary venous return obstruction [1]. Disease natural history shows that $20 \%$

1. Specialist; Cardiovascular Surgeon.

2. Specialist; Pediatric Cardiologist.

3. PhD Student; Pediatric Cardiologist.

4. PhD Student; Cardiovascular Surgeon.

This study was carried out at Heart Institute of Distrito Federal, Zerbini Foundation, Brasília, DF, Brazil.

\section{Resumo}

Paciente de 22 anos, sexo masculino, foi admitido com conexão anômala total de veias pulmonares, supracardíaca, não-obstrutiva, com grande comunicação interatrial. $O$ cateterismo cardíaco revelou hipertensão pulmonar importante secundária a hiperfluxo pulmonar $(\mathrm{Qp}: \mathrm{Qs}=6$, resistência vascular pulmonar $1,6 \mathrm{Woods} / \mathrm{m}^{2}$ ). A operação corretiva foi realizada por meio de esternotomia mediana e circulação extracorpórea, e o paciente obteve alta hospitalar no sexto dia de pós-operatório, sem complicações, em uso de inibidor da enzima conversora e aspirina. No seguimento de 6 meses após a operação, encontra-se assintomático com função biventricular preservada e sem sinais ecocardiográficos de hipertensão pulmonar.

Descritores: Cardiopatias congênitas. Hipertensão pulmonar. Veias pulmonares/anormalidades.

survive until the first year of life without treatment [2].

Exceptionally, symptoms may appear later in life, depending on the absence of pulmonary venous obstruction and the occurrence of large intracardiac septal defects which allow right-to-left shunts [3]. Nonetheless, the presence of advanced pulmonary hypertension is common.

We aim to report a case of an adult patient with supracardiac TAPVC successfully undergone complete repair.

Correspondence address: Fernando Atik

Instituto do Coração do Distrito Federal, Fundação Zerbini Estrada Parque Contorno do Bosque s/n, 1 andar, sala 13 - Brasília, DF, Brasil - CEP: 70658-700.

E-mail: fernando.atik@incordf.zerbini.org.br

Article received on July $28^{\text {th }}$, 2008 Article accepted on November $27^{\text {th }}$, 2008 


\section{CASE REPORT}

A 22-year-old man complained of dyspnea on exertion and nonproductive cough initiating 6 years ago. At that time, he was diagnosed with congenital heart disease. Although surgery was offered as the treatment of choice, he denied it due to social reasons. However, his symptoms have got worse in the latest years in terms of dyspnea associated with palpitations, blurry vision, palish skin and cold sweats at extremities that appeared on normal activities.

On physical exam, he was found well, breathing confortably and with no cyanosis (94\% room air oxygen saturation). Chest was inflated, hyperdynamic, ictus visible and palpable at left sixth intercostal space, mid clavicle line. Cardiac auscultation revealed regular heart rhythm, wide and fixed splitting of the second heart sound with accentuation of the pulmonary component, and $++/ 6$ systolic murmur at pulmonary area. Abdomen was flat and liver was not palpable. Peripheral pulses were symmetric and there was no peripheral edema.

Chest radiograph showed mild heart enlargement related to right atrium and heart format resembled a "snowman" (Figure 1). Lung fields were clear and there were signs of hilar pulmonary congestion. Electrocardiography revealed sinus rhythm, 66 beats per minute, first-degree atrioventricular block $(\mathrm{PR}=220 \mathrm{~ms})$, ventricular depolarization electric axis 160 degrees and right atrium potentials. Two-dimensional echocardiography confirmed the diagnosis of nonobstructive, supracardiac total anomalous pulmonary venous connection through the superior vena cava. There was a 13 millimeter atrial septal defect with unidirectional right-to-left shunt and severe right heart enlargement with preserved biventricular systolic function. Right ventricular systolic pressure was estimated as $50 \mathrm{mmHg}$, and there was severe pulmonary overflow (Qp:Qs=3.3).

Right heart catheterization was performed in order to have a more detailed assessment of hemodynamic parameters and anatomic substrate. It was determined the presence of severe pulmonary hypertension (systolic pulmonary artery pressure $60 \mathrm{mmHg}$, pulmonary wedge pressure $16 \mathrm{mmHg}$ and transpulmonary gradient $19 \mathrm{mmHg}$ ) secondary to pulmonary overflow (Qp:Qs=6, indexed pulmonary vascular resistance $1.6 \mathrm{Woods} / \mathrm{m}^{2}$ ).

Complete repair was performed through median sternotomy and hypothermic cardiopulmonary bypass. There was marked right heart enlargement, and supracardiac total pulmonary venous connection through the inominate vein was confirmed. Surgical access was posterior, through the transverse sinus, and latero-lateral anastomosis was constructed between the pulmonary venous confluence and the left atrium dome using part of the left atrial appendage.
Although these structures were markedly larger than in the neonate, there was some excessive distance between them, making harder the surgical repair. In order to eliminate these problems, we choose to extend the posterior anastomotic suture line with a fresh autologous pericardial patch, distributing more homogenously the anastomotic tension. Pulmonary venous confluence was ligated nearby the inominate vein. Postoperative course was uneventful, and pulmonary artery pressure remained around $50 \%$ of systemic pressure, with no need for specific measures to control pulmonary hypertension. Patient was discharged from hospital on sixth postoperative day with no residual problems. At six-month follow-up, he is currently on New York Heart Association functional class I, with preserved biventricular function and no echocardiographic signs of pulmonary hypertension.

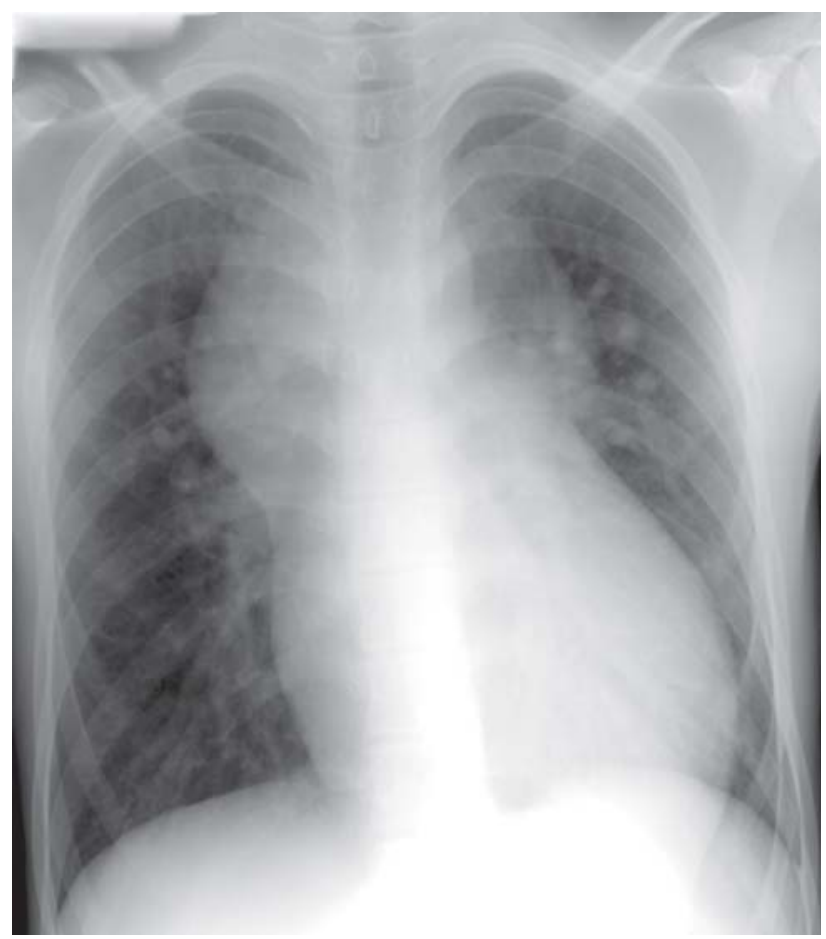

Fig. 1 - Chest radiography in postero-anterior, showing heart format resembling a "snowman"

\section{DISCUSSION}

The present case shows that a minority of patients with nonobstructive TAPVC may reach adulthood with no fixed pulmonary hypertension. The reason for that relies on large atrial septal defect, resembling other reports in the literature $[4,5]$. 
Nevertheless, it is important that adult TAPVC patients should thoroughly assessed preoperatively with right heart catheterization, in order to detect patients in late stages of pulmonary hypertension which may either contraindicate total repair or help in planning intra and postoperative management for those cases suitable for repair. In that instance, intra and postoperative pulmonary artery monitoring is important to identify adequate response to therapeutic measures aiming pulmonary vascular resistance reduction.

It is widely known that chronic pulmonary overflow determines progressive right heart dilation and pulmonary hypertension that impair systemic venous return. As a consequence, vena cava are extremely dilated and fixed in the adult, impairing surgical exposure and subsequent surgical technique.

In order to minimize these problems, Nigro et al. [6] described an alternative technique that aims to improve surgical exposure of transverse sinus by transecting and retracting superiorly the vena cava. In the present case, we did not experience any surgical exposure issue. However, the left atrium dome and pulmonary venous confluence were not tied together, even after their full mobilization. Extending the posterior anastomotic line with fresh autologous pericardium distributed more homogeneously the anastomotic tension, minimizing eventual bleeding sites.

The existing controversy on neonatal repair on whether pulmonary venous confluence ligation should be performed does not seem applicable in adult patients. Left atrial size is sufficiently large in the latter, and low cardiac output syndrome due to diastolic dysfunction would not be justified.
In conclusion, adult patients with TAPVC can be repaired when there is no fixed pulmonary hypertension. Patients should be carefully selected for surgery, as well as their intraoperative and postoperative management, in order to achieve a satisfactory outcome.

\section{REFERENCES}

1. Atik FA, Irun PE, Barbero-Marcial M, Atik E. Total anomalous drainage of the pulmonary veins: surgical therapy for the infradiaphragmatic and mixed anatomical types. Arq Bras Cardiol. 2004;82(3):259-63.

2. Burroughs JT, Edwards JE. Total anomalous venous connection. Am Heart J. 1960;59:913-31.

3. Nurkalem Z, Gorgulu S, Eren M, Bilal MS. Total anomalous pulmonary venous return in the forth decade. Int J Cardiol. 2006;113(1):124-6.

4. Vicente WV, Dias-da-Silva PS, Vicente LM, Bassetto S, Romano MM, Ferreira CA, et al. Surgical correction of total anomalous pulmonary venous drainage in an adult. Arq Bras Cardiol. 2006;87(5):e172-5.

5. Juneja R, Saxena A, Kothari SS, Taneja K. Obstructed infracardiac total anomalous venous connection in an adult. Pediatr Cardiol. 1999;20(2):152-4.

6. Nigro JJ, Choi S, Graziano J, Gandy KL, Guerrero-Tiro LM, Cleveland DC. Modified superior repair of supracardiac total anomalous pulmonary venous connection in the adult. Ann Thorac Surg. 2007;84(1):312-3. 